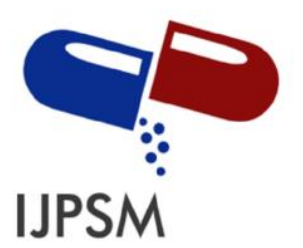

Iffah Anasia et al, Int. Journal of Pharmaceutical Sciences and Medicine (IJPSM),

Vol.6 Issue. 8, August- 2021, pg. 161-172

ISSN: 2519-9889

Impact Factor: 3.426

\title{
REVIEW: REMDESIVIR AS A CANDIDATE FOR COVID-19 TREATMENT
}

\author{
Iffah Anasia ${ }^{1}$; Zulharmita ${ }^{2}$; Ridho Asra ${ }^{3 *}$ \\ School of Pharmaceutical Science, Padang, West Sumatra, Indonesia \\ Email: ridhoasra@gmail.com \\ DOI: 10.47760/ijpsm.2021.v06i08.012
}

\begin{abstract}
Remdesivir is the first drug that has been approved by the US Food and Drug Administration (FDA) for clinical use in hospitalized patients with COVID-19 disease.

From several therapeutic options, Remdesivir is a direct-acting antiviral drug that has previously been tested against the Ebola virus, known to be effective and safe enough to inhibit the replication of SARS-CoV-2.

Corona virus or severe acute respiratory syndrome coronavirus 2 (SARS-CoV-2) is a virus that attacks the respiratory system in humans, this virus can cause mild disorders of the respiratory system, severe lung infections, and even death.

Remdesivir is a broad-spectrum antiviral agent that has previously shown antiviral activity against filoviruses (Ebola and Marburg viruses), coronaviruses (SARS-CoV, MERS-CoV, SARS CoV-2), paramyxoviruses (type III influenza virus, Nipah virus, Hendra virus, measles, and mumps virus) and Pnemoviriidae (respiratory syncytial virus).
\end{abstract}

\section{Keywords: Remdesivir; COVID-19; SARS-CoV-2; Ebola virus}

\section{Introduction}

The world is currently facing a pandemic and the cause of this pandemic (Covid-19) is Severe Acute Respiratory Syndrome Coronavirus 2 (SARS-CoV-2). However, there are no specific antiviral drugs available for the treatment of Covid-19. Remdesivir is a broadspectrum antiviral drug that works by inhibiting RNA-dependent RNA polymerase. It is a prodrug and upon activation in the host cell is converted to the active form, Remdesivir nucleoside triphosphate (adenosine triphosphate analog) which competes with ATP, for 


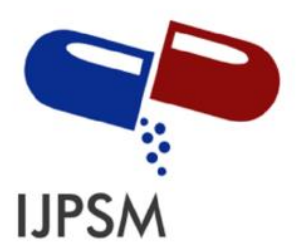

Iffah Anasia et al, Int. Journal of Pharmaceutical Sciences and Medicine (IJPSM), Vol.6 Issue. 8, August- 2021, pg. 161-172

ISSN: 2519-9889

Impact Factor: 3.426

inclusion in viral RNA. This leads to the termination of RNA polymerase-dependent RNA chain elongation. In various studies Remdesivir has shown promising effects for the management of Covid-19, the US FDA has issued an Emergency Use Authorization (EUA) for its use in the management of Covid-19 but the latest WHO recommendations do not promote it [1].

The recent outbreak of the novel coronavirus disease (COVID-19), caused by acute respiratory syndrome coronavirus 2 (SARS-CoV-2), is seeing a rapid increase in infected patients worldwide. The host immune response to SARS-CoV-2 is important in disease pathogenesis and clinical manifestations. SARS-CoV-2 not only activates the antiviral immune response, but can also induce an uncontrolled inflammatory response characterized by the release of proinflammatory cytokines in patients with severe COVID-19, leading to lymphopenia, lymphocyte dysfunction, and granulocyte and monocyte abnormalities. This SARS-CoV-2-induced immune disorder can cause infection by microorganisms, septic shock, and severe multiple organ dysfunction[2].

Remdesivir is one of the most promising drugs to treat COVID-19 based on the following facts: remdesivir has a broad spectrum antiviral mechanism of action demonstrated in vitro activity against SARS-CoV-2 and in vivo efficacy in animal models, its safety profile has been tested in Ebola patients and in COVID-19 patients. Currently, remdesivir is being investigated in ten randomized controlled trials against COVID-19. The dosing regimen of remdesivir is an IV loading dose of $200 \mathrm{mg}$ on the first day followed by a $100 \mathrm{mg}$ intravenous (iv) dose for 5-9 days. Based on data analysis, remdesivir by iv administration alone is unlikely to achieve excellent clinical efficacy. This analysis is based on observations of remdesivir plasma exposure and metabolite activity unlikely to correlate with clinical efficacy, remdesivir and active metabolites are unlikely to be sufficient in the lung to kill the SARS-CoV-2 virus. Even if remdesivir shows benefit in current randomized controlled trials its efficacy will be limited. It is suggested that combination iv administration dosing regimens should be studied to realize a potentially more effective antiviral therapy against COVID$19[3]$. 


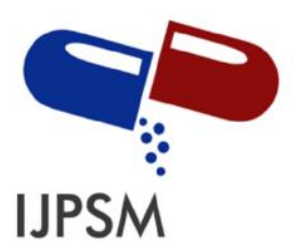

Iffah Anasia et al, Int. Journal of Pharmaceutical Sciences and Medicine (IJPSM), Vol.6 Issue. 8, August- 2021, pg. 161-172

ISSN: 2519-9889

Impact Factor: 3.426

Remdesivir has recently been recognized as a promising antiviral drug against various RNA viral infections (including SARS/MERS-CoV5) in the cultured cell, mouse, and nonhuman primate (NHP) models. It is currently in clinical development for the treatment of Ebola virus infection. Remdesivir is an adenosine analog that is incorporated into the RNA chain of newborn viruses and successfully stops the virus from growing more rapidly [4].

\section{METHODS AND DATA COLLECTION}

In writing this review article, the methods used are literature studies relevant to the purpose of the review. Sources of information are from national journals and international journals that are accessed through online sites such as Google Scholar, PubMed, FDA, and NCBI. To find the journals, the keywords used were as follows: Remdesivir, COVID-19, SARS-CoV-2, and the Ebola virus.

\section{RESULTS AND DISCUSSION}

\section{Discovery and analysis of the structure of Remdesivir}

In early 2020, the world was shocked by the disease caused by a new coronavirus which was named COVID-19 by the World Health Organization (WHO 2). The causative agent of this infection is severe acute respiratory syndrome coronavirus 2 (SARS-CoV-2). Available data on one of the promising therapeutic agents nucleotide analog remdesivir (Gilead Sciences number GS-5734) was evaluated. These data relate to the activation of remdesivir from the prodrug to an active triphosphate molecule containing a 1'-cyano group and a modified nucleobase. This triphosphate competes with the natural substrate adenosine triphosphate. Moreover, its mechanism of action is based on RNA and proofreading of exonuclease inhibition leading to delayed RNA chain termination of infected cells and basic pharmacological data. In addition, the determination of the analysis of remdesivir and its metabolites in cells and body fluids was done based on the data from the use of remdesivir in other RNA infections such as Ebola, Nipah virus infection, and Middle East Respiratory Syndrome (MERS). More recent and more detailed data on the clinical use of remdesivir in 


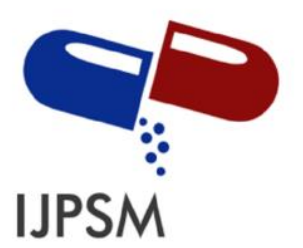

Iffah Anasia et al, Int. Journal of Pharmaceutical Sciences and Medicine (IJPSM), Vol.6 Issue. 8, August- 2021, pg. 161-172

ISSN: 2519-9889

Impact Factor: 3.426

COVID-19 reportedly demonstrate the intensive efforts of doctors and scientists to develop a drug for this new disease. Remdesivir thus represents one of the more promising alternatives for COVID-19 therapy, however, the current understanding of the disease and possible ways to treat it requires further investigation[5].

The development of remdesivir has become a new breakthrough for the treatment of COVID19. It has been approved in about 50 countries including Saudi Arabia since 2020. The generic structure of remdesivir was first disclosed in 2009. This review summarizes the findings based on remdesivir for treating or preventing COVID-19 and other disorders from 2009 to May 16, 2021 emphasizing its relevance to medical and pharmaceutical sciences. The main uses of remdesivir are related to its composition, novel combinations with other therapeutic agents, administration, and indications. The inventive combination has shown a synergistic effect against COVID-19, the findings associated with a new indication of remdesivir for treating Ebola, hepatitis, idiopathic pulmonary fibrosis, diabetic nephropathy, and cardiovascular complications increase its therapeutic area. Many new innovative combinations and remdesivir delivery systems are anticipated to provide better treatment for COVID-19[6]

Remdesivir was first identified during extensive screening for compounds with emerging virus-fighting activity. The screening program was used to identify candidates that could inhibit Coronaviridae and Flaviviridae RNA viruses. Following the 2013-2016 EVD outbreak in West Africa, several previously investigated compounds were further investigated against EBOV. Remdesivir was observed to have high potency against EBOV in several cell lines with a half-maximal effective concentration (EC50) of anti-EBOV 0.086 M in human macrophages. Remdesivir was selected for further clinical development based on its potency and chemical structure which can be enhanced more rapidly [7]. 


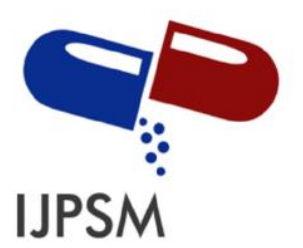

Iffah Anasia et al, Int. Journal of Pharmaceutical Sciences and Medicine (IJPSM), Vol.6 Issue. 8, August- 2021, pg. 161-172

ISSN: 2519-9889

Impact Factor: 3.426

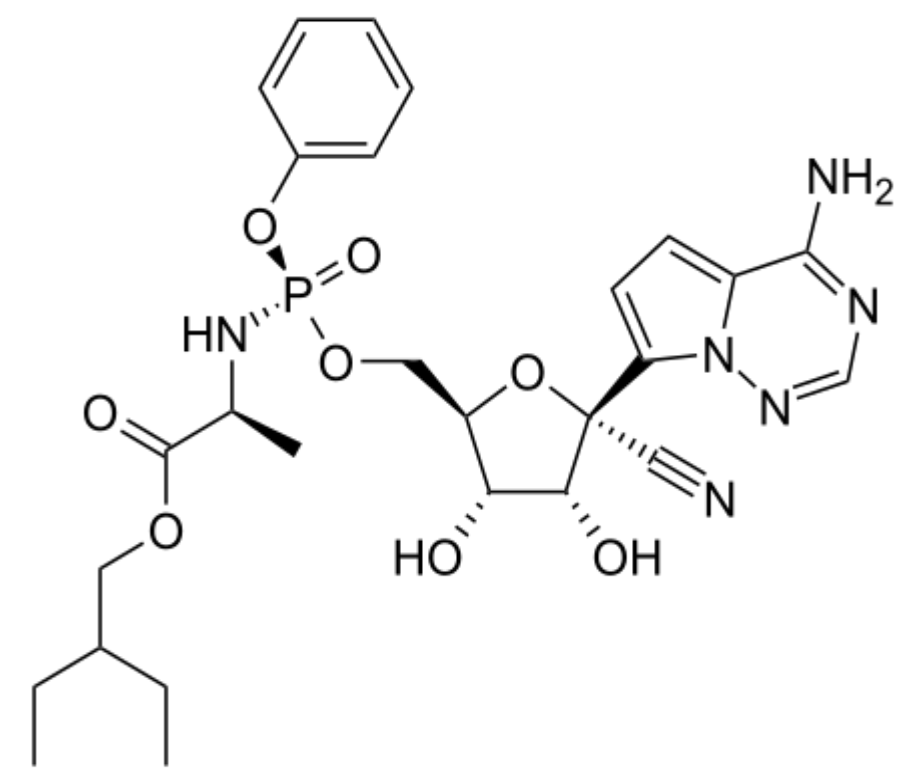

Figure 1. Chemical structure of Remdesivir C27H35N6O8P, synonym GS 5734

\section{PRECLINICAL DEVELOPMENT}

\section{Pharmacology}

Remdesivir (GS-5734 chemical formula C27H35N6O8P) is a monophosphoramidate prodrug of the nucleoside analog C-adenosine. Remdesivir stops viral RNA synthesis by inhibiting viral RNA-dependent RNA polymerase ( $\mathrm{RdRp})$. The active form remdesivir triphosphate competes with native adenosine triphosphate for chain inclusion resulting in delayed chain termination. Remdesivir displays linear pharmacokinetics and a long intracellular half-life (>35 hours for the active parent triphosphate). Remdesivir triphosphate was found to accumulate in peripheral blood mononuclear cells, suggesting a loading dose that may accelerate the achievement of a stable state. These characteristics support the dosing regimen used in clinical studies to date: $200 \mathrm{mg}$ intravenously on the first day, followed by $100 \mathrm{mg}$ intravenously once daily (5-10 days total)[7]. 


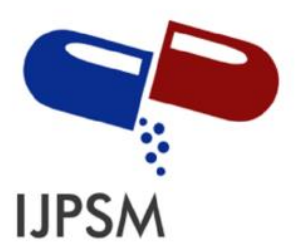

Iffah Anasia et al, Int. Journal of Pharmaceutical Sciences and Medicine (IJPSM), Vol.6 Issue. 8, August- 2021, pg. 161-172

ISSN: 2519-9889

Impact Factor: 3.426

\section{In silico test}

The in silico test showed that Remdesivir had good docking scores with strong and stable binding affinity with important residues Cys145 and His164 of Mpro that inhibited 2019$\mathrm{nCoV}$ replication and proliferation [8].

\section{In vitro test}

1. In 2016, remdesivir was reported to be active against Ebola virus, including primary macrophages of human endothelial cells with a low half-maximum effective concentration value of $0.06-0.14 \mathrm{M}[9]$.

2. Remdesivir has been reported to show activity in vitro against Marburg virus, Paramyxoviridae (influenza type III, Nipah virus, Hendra virus, Measles virus, Mumps virus), and Pneumoviridae (respiratory syncytial virus)[10].

\section{In vivo test}

In 2016 an in vivo study was conducted using rhesus-infected Ebola monkeys and various doses of remdesivir intramuscular injections, which later revealed that remdesivir exerts a protective effect by inhibiting viral replication. The concentration of the remdesivir form was $10 \mu \mathrm{M}$ in peripheral blood mononuclear cells after administration of $10 \mathrm{mg} / \mathrm{kg}$ remdesivir. Studies on African green monkeys infected with Nipah virus showed a protective effect of remdesivir, half of the monkeys treated with remdesivir developed mild respiratory symptoms and the other half recovered, those from the control group developed severe respiratory disease. Remdesivir treatment was found to reduce viral load in MERS-CoVinfected mice and was phenotypically associated with improved lung function and decreased likelihood of developing acute lung injury in infected animals. In addition, remdesivir inhibited MERS-CoV replication in the lungs of rhesus macaques and led to a reduction in lung lesions. Remdesivir also reduced viral load in the lungs and improved respiratory function in mice infected with SARS-CoV-2, improving lung lesions, according to radiographs reducing viral titers in bronchoalveolar lavage after 12 hours of treatment, and 


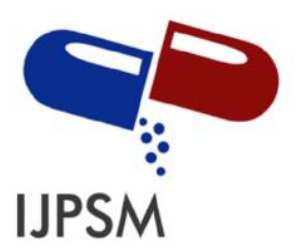

Iffah Anasia et al, Int. Journal of Pharmaceutical Sciences and Medicine (IJPSM), Vol.6 Issue. 8, August- 2021, pg. 161-172

ISSN: 2519-9889

Impact Factor: 3.426

reducing viral load in lungs after 7 days of treatment. Even animals treated with remdesivir showed no signs of lung disease[11].

\section{Toxicity test}

None of the clinical trials have demonstrated any toxicity associated with remdesivir. However, in a randomized, placebo-controlled phase of the study that developed the pharmacokinetics, tolerability and safety profile of single-dose and multidose remdesivir in subjects, it was reported that remdesivir was well tolerated without serious toxic effects or death associated with its clinical use [12].

\section{Hepatotoxicity}

There are no data on remdesivir drug interactions, possibly because there are no interactions or data related to remdesivir interactions. Currently remdesivir has an EUA from the FDA for the treatment of COVID-19[13].

\section{CLINICAL TESTING}

Several clinical trials are underway for the management of COVID-19 using Remdesivir. The efficacy of Remdesivir (GS-5734) against the Ebola virus has been demonstrated. In the field of Medical Sciences, the definition of the topological index on molecular structure and medical, biological, chemical, pharmaceutical properties of suitable drugs can be studied by calculating the topological index. There are several inverted topological indices, namely, inverted general Randic index, inverted atomic bond connectivity index, inverted geometric arithmetic index, inverted forgetting index, inverted Balaban index, and inverted Zagreb type index [14]. 


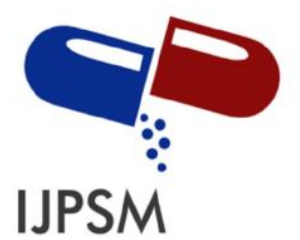

Iffah Anasia et al, Int. Journal of Pharmaceutical Sciences and Medicine (IJPSM),

Vol.6 Issue. 8, August- 2021, pg. 161-172

ISSN: 2519-9889

Impact Factor: 3.426

\section{Asymmetric synthesis of Remdesivir catalyst}
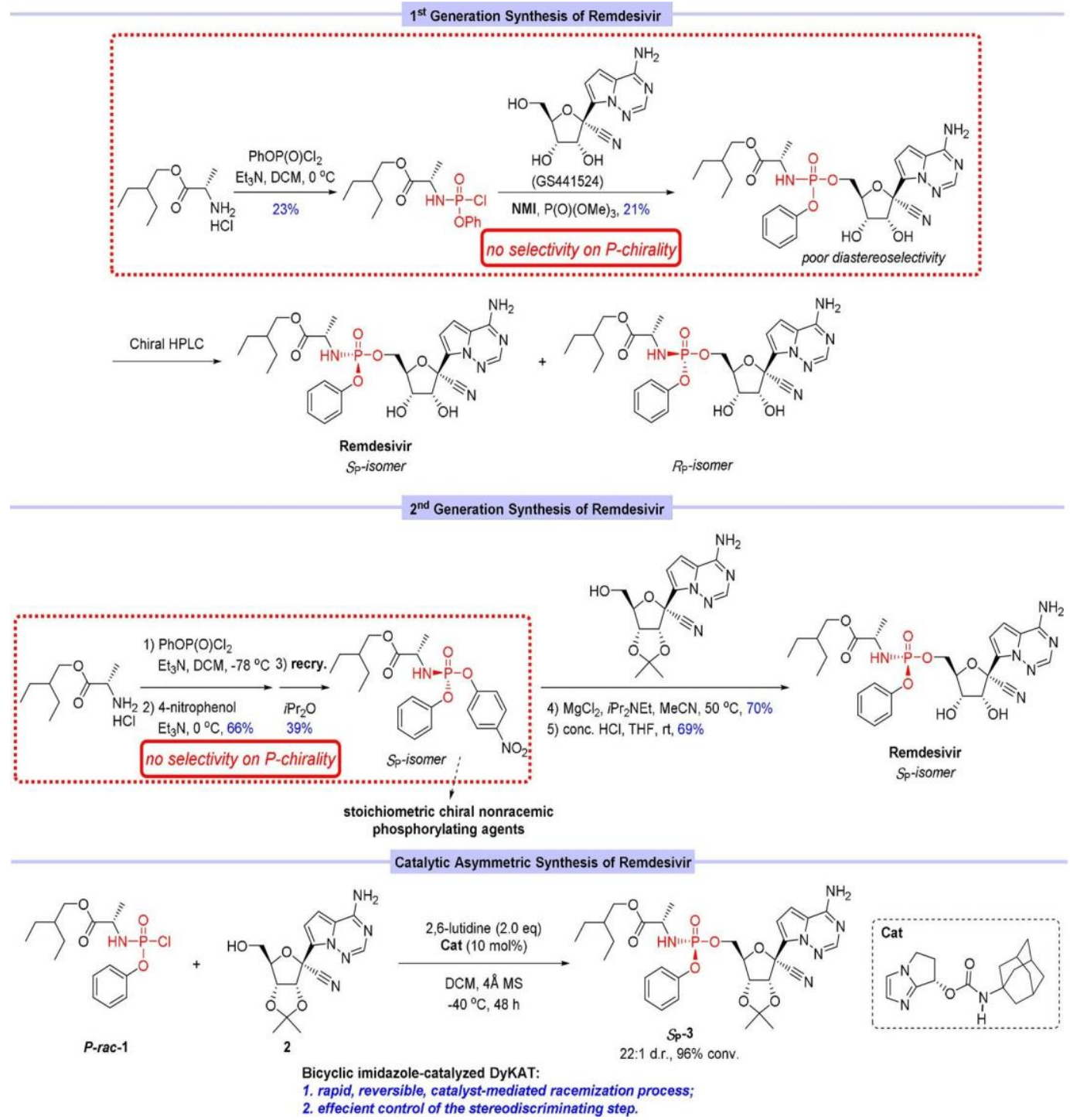

Specific performance of chiral bicyclic imidazoles in the catalytic asymmetric synthesis of Pracemic phosphoryl chloride 1 and nucleoside 2-protected remdesivir (Table 1). The reaction was uncatalyzed and it was found that only a small amount of product 3 with 1.1:1 dr 


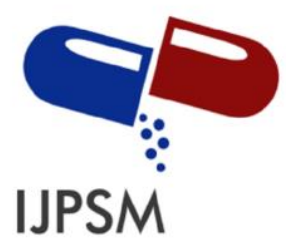

Iffah Anasia et al, Int. Journal of Pharmaceutical Sciences and Medicine (IJPSM),

Vol.6 Issue. 8, August- 2021, pg. 161-172

ISSN: 2519-9889

Impact Factor: 3.426
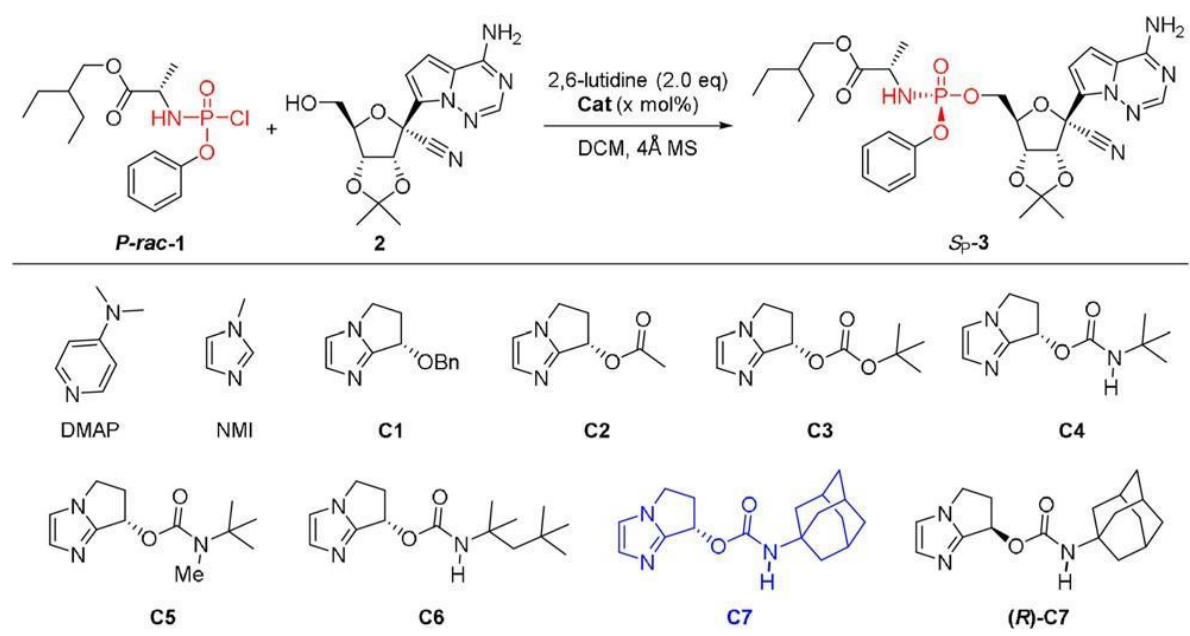

\begin{tabular}{|c|c|c|c|c|c|c|}
\hline Entry & mole\% Cat & Base & $T[\mathbf{8 C}]$ & $t[\mathrm{~h}]$ & $S_{\mathrm{P}} / R_{\mathrm{P}}^{[\mathrm{b}]}$ & Conv. $[\%]^{[\mathrm{c}]}$ \\
\hline 1 & none & 2,6-lutidine & -10 & 16 & 1.1 .1 & 3 \\
\hline 2 & $20 \%$ DMAP & 2,6-lutidine & -10 & 16 & $1.1: 1$ & 33 \\
\hline 3 & $20 \% \mathrm{NMI}$ & 2,6-lutidine & -10 & 16 & $1.5: 1$ & 62 \\
\hline 4 & $20 \% \mathrm{C} 1$ & 2,6-lutidine & -10 & 16 & $3.2: 1$ & 45 \\
\hline 5 & $20 \% \mathrm{C} 2$ & 2,6-lutidine & -10 & 16 & 2.6:1 & 63 \\
\hline 6 & $20 \% \mathrm{C} 3$ & 2,6-lutidine & -10 & 16 & 1.9:1 & 46 \\
\hline 7 & $20 \% \mathrm{C} 4$ & 2, 6-lutidine & -10 & 16 & $9.3: 1$ & 91 \\
\hline 8 & $20 \% \mathrm{C} 5$ & 2,6-lutidine & -10 & 16 & $6.2: 1$ & 47 \\
\hline 9 & $20 \% \mathrm{C} 6$ & 2,6-lutidine & -10 & 16 & $7.4: 1$ & 83 \\
\hline 10 & $20 \% \mathrm{C} 7$ & 2,6- lutidine & -10 & 16 & $11.2: 1$ & 91 \\
\hline 11 & $20 \%(R)-\mathrm{C} 7$ & 2,6-lutidine & -10 & 16 & $4.3: 1$ & 81 \\
\hline 12 & $20 \% \mathrm{C} 7$ & none & -10 & 16 & $7.8: 1$ & 77 \\
\hline 13 & $20 \% \mathrm{C} 7$ & 2,6-lutidine & -30 & 16 & $16.6: 1$ & 96 \\
\hline 14 & $20 \% \mathrm{C} 7$ & 2,6-lutidine & -40 & 36 & 21.8:1 & 96 \\
\hline
\end{tabular}




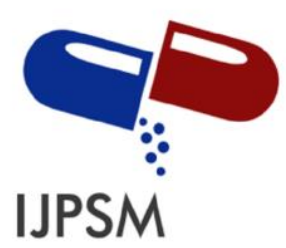

Iffah Anasia et al, Int. Journal of Pharmaceutical Sciences and Medicine (IJPSM), Vol.6 Issue. 8, August- 2021, pg. 161-172

ISSN: 2519-9889

Impact Factor: 3.426

\begin{tabular}{|ccccccc|}
\hline 15 & $10 \%$ C7 & 2,6-lutidine & -30 & 36 & $16.4: 1$ & 95 \\
\hline 16 & $5 \%$ C7 & 2,6-lutidine & -30 & 48 & $16.4: 1$ & 94 \\
\hline 17 & $10 \%$ C7 & 2,6-lutidine & -40 & 48 & $21.6: 1$ & 96 \\
\hline
\end{tabular}

[a] Reaction conditions: P-rac-1 (104.3 mg, $0.30 \mathrm{mmol}, 1.5$ equiv), 2 ( $66.3 \mathrm{mg}, 0.20 \mathrm{mmol}$, 1.0 equivalent), 2.6-lutidine ( $46.6 \mathrm{~mL}, 0.40 \mathrm{mmol}, 2.0$ equivalent), $4 \mathrm{MS}$ (80 mg), DCM (2 $\mathrm{mL}$ ). [b] Determined by 31P NMR analysis. [c] Determined by 31P NMR analysis using $\mathrm{P}(\mathrm{O})(\mathrm{OMe}) 3$ as internal standard.

Based on the table above, there is a potential for increased reactivity and stereocontrol of this phosphorylation process. Accordingly, various nucleophilic catalysts containing the developed chiral bicyclic imidazole framework were screened in the transformation. This catalyst is modified with benzyl ether $\mathrm{C} 1$, acetyl ester $\mathrm{C} 2$, tertbutyl carbonate $\mathrm{C} 3$, and various C4-C7 carbamates (entries 4-10). A C4 catalyst containing a carbamate group was identified as a superior catalyst motif providing the desired phosphoramide product in high conversion $(91 \%)$ and selectivity of 9.3:1 favoring the desired configuration in the phosphorus center. The absolute configuration of the P-stereocenter on remdesivir (entry 7). The C5 catalyst containing a methyl substituent on the carbamate group showed poorer stereocontrol than the P-stereocenter (entry 8). Subsequently, C6 and C7 catalysts containing carbamate groups with greater steric resistance were synthesized and applied to this reaction to further enhance the stereoselectivity (entries 9 and 10). C7 catalyst modified with adamantinyl group gave good results (11.2:1 dr, 91\% conv.). An incompatible relationship was observed by changing the C7 enantiopure configuration between the chiral catalyst and the substrate (entry 11). In the absence of base, the desired product is obtained in reduced conversion (entry 12, 7.8:1 dr, $77 \%$ conv.). The apparent decrease in reactivity and selectivity suggests that the base 2,6lutidine can participate in the transition state of the rate-determining and stereodiscrimination steps. To further increase the diastereoselectivity, the reaction temperature was reduced to $308 \mathrm{C}$ and $408 \mathrm{C}$, and the selectivity was increased to $16.6: 1$ and 21.8:1 with comparable reactivity, respectively (entries 13 and 14). When the catalyst loading was 


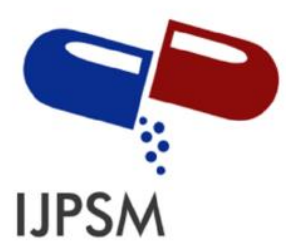

Iffah Anasia et al, Int. Journal of Pharmaceutical Sciences and Medicine (IJPSM), Vol.6 Issue. 8, August- 2021, pg. 161-172

ISSN: 2519-9889

Impact Factor: 3.426

reduced to $10 \mathrm{~mol} \%$ and $5 \mathrm{~mol} \%$, longer reaction times were required but comparable diastereoselectivity was obtained (entries 13-17). These results indicate that the value is independent of the catalyst concentration. Thus, the desired product can be obtained in $94 \%$ conversion with 16.4:1 dr and 96\% conversion with 21.6:1 dr at $5 \mathrm{~mol} \%$ (30 8C) and 10 mol\% ( 40 8C) catalyst load, respectively. (entries 16 and 17)[15].

\section{CONCLUSION}

Remdesivir is one of the candidates for the treatment of patients exposed to the coronavirus. In vivo and in vitro studies have shown the efficacy of remdesivir against the coronavirus by toxicity tests without showing serious side effects in patients.

\section{REFERENCES}

[1]. Agrawal A, Kashikar S, Gaidhane A, Bansod A, Jaiswal P, Khatib MN. Severe Acute Respiratory Coronavirus-2: A Critical Review of Virus Biology, Genome and Pathophysiology. The Open Dentistry Journal. 2021 Jul 12;15(1).

[2]. Yang L, Liu S, Liu J, Zhang Z, Wan X, Huang B, Chen Y, Zhang Y. COVID-19: immunopathogenesis and Immunotherapeutics. Signal transduction and targeted therapy. 2020 Jul 25;5(1):1-8.

[3]. Sun D. Remdesivir for treatment of COVID-19: combination of pulmonary and IV administration may offer additional benefit. The AAPS journal. 2020 Jul;22:1-6.

[4]. Wang M, Cao R, Zhang L, Yang X, Liu J, Xu M, Shi Z, Hu Z, Zhong W, Xiao G. Remdesivir and chloroquine effectively inhibit the recently emerged novel coronavirus (2019-nCoV) in vitro. Cell research. 2020 Mar;30(3):269-71.

[5]. Al-Tannak NF, Novotny L, Alhunayan A. Remdesivir-bringing hope for COVID-19 treatment. Scientia Pharmaceutica. 2020 Jun;88(2):29.

[6]. Imran M, Asdaq SM, Khan SA, Meenakshi DU, Alamri AS, Alsanie WF, Alhomrani M, Mohzari Y, Alrashed A, AlMotairi M, Alkhaldi EH. Innovations and Patent Trends in the Development of USFDA Approved Protein Kinase Inhibitors in the Last Two Decades. Pharmaceuticals. 2021 Aug;14(8):710.

[7]. Pardo J, Shukla AM, Chamarthi G, Gupte A. The journey of remdesivir: from Ebola to COVID-19. Drugs in context. 2020;9.

[8]. Naik VR, Munikumar M, Ramakrishna U, Srujana M, Goudar G, Naresh P, Kumar BN, Hemalatha R. Remdesivir (GS-5734) as a therapeutic option of 2019-nCOV main protease-in silico approach. Journal of Biomolecular Structure and Dynamics. 2020 Jun 20:1-4.

[9]. Wang M, Zhang L, X Huo, Zhang Z, Yuan Q, Li P, Chen J, Zou Y, Wu Z, Zhang W. Catalytic Asymmetric Synthesis of the anti-COVID-19 Drug Remdesivir. Angewandte Chemie International Edition. 2020 Nov 16;59(47):20814-9.

[10]. Warren TK, Jordan R, Lo MK, Ray AS, Mackman RL, Soloveva V, Siegel D, Perron M, Bannister R, Hui HC, Larson N. Therapeutic efficacy of the small molecule GS-5734 against Ebola virus in rhesus monkeys. Nature. 2016 Mar;531(7594):381-5.

[11]. Frediansyah A, Nainu F, Dhama K, Mudatsir M, Harapan H. Remdesivir and its antiviral activity against COVID-19: A systematic review. Clinical epidemiology and global health. 2021 Jan 1;9:123-7. 


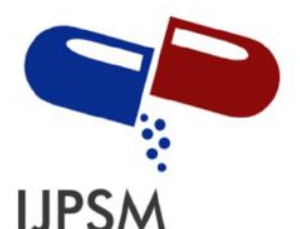

Iffah Anasia et al, Int. Journal of Pharmaceutical Sciences and Medicine (IJPSM), Vol.6 Issue. 8, August- 2021, pg. 161-172

ISSN: 2519-9889

Impact Factor: 3.426

[12].Aleem A, Kothadia J. Remdesivir. StatPearls. 2021 Apr 8.

[13].Faizah AK, Nurrahman NW, Putra ON. A Mini Review: Clinically Significant Potential Drug-Drug Interactions in COVID-19 and Comorbid Therapy. Pharmaceutical Sciences and Research. 2020;7(4):3.

[14].Naik VR, Munikumar M, Ramakrishna U, Srujana M, Goudar G, Naresh P, Kumar BN, Hemalatha R. Remdesivir (GS-5734) as a therapeutic option of 2019-nCOV main protease-in silico approach. Journal of Biomolecular Structure and Dynamics. 2020 Jun 20:1-4. 